\title{
Reminiscences of a Statistician: The Company I Kept
}

\section{Erich L. Lehmann}

Springer, 2008, xii $\ddot{i} 309$ pages, 34.94 / US\$ 44.95, softcover

ISBN: 978-0-387-71596-4

Table of contents

1. Mathematical preparation

2. Becoming a statistician

3. Early collaborators

4. Mathematical statistics at other universities

5. The Annals

6. The Berkeley Statistics Department I: Establishment and first generation

7. The Berkeley Statistics Department II: The second generation
8. The Stanford Statistics Department
9. Nonparametrics and robustness
10. Foundations I: The frequentist approach
11. Foundations II: Bayesianism and data analysis
12. Statistics comes of age
13. New tasks and relationships
14. England
15. Contacts abroad

Readership: For anyone interested in the people and ideas from the academic side of our profession over the last 75 years.

This book is a gem, a must-read. It is a thoroughly enjoyable mixture of autobiographical and broader historical material, presented as mini-biographies of over 60 mathematicians and statisticians connected to the author, these being grouped by time, place or a scientific or personal theme. Lehmann is extremely well known in the statistical world for his research contributions, and his books on testing, estimation, nonparametrics, and introductory statistics, which have been widely used for decades, and translated into many languages other than their original English. The wonderful writing style which makes his texts so popular shines out in this one. He suggests early on in the book that as a teenager his love was German literature, and that perhaps he would have become a writer, had circumstances in his native Germany not dictated otherwise. Instead he became a mathematician, and later a statistician. A reader of this volume will come away with the distinct impression that he realized this early ambition, though perhaps not quite as he originally imagined.

There are so many fascinating pieces in this book that it is probably unwise to single any out, but I cannot resist doing so. The portrait of the German mathematician Edmund Landau is a delight, showing a side to him and recounting his final, sad years in a way that cannot fail to amuse and move the reader. The book contains many anecdotes relating to what we might call career development, implicitly emphasizing the role of chance in life. It contains much of interest on academic research, administration, teaching, the writing of papers and textbooks, collaboration, advising and, most prominently, friendship. It is also full of photos of those who people the book. 